\title{
ANALISIS BANJIR DAN PEMETAAN KAWASAN TERDAMPAK BANJIR DI KELURAHAN LAWEYAN, KOTA SURAKARTA
}

\author{
Edo Suryo Utomo ${ }^{1)}$, Rintis Hadiani ${ }^{2}$, Endah Sitaresmi Suryandari ${ }^{3)}$ \\ 1) Mahasiswa Fakultas Teknik, Prodi Teknik Sipil, Universitas Sebelas Maret \\ 2) Pengajar Fakultas Teknik, Prodi Teknik Sipil, Universitas Sebelas Maret \\ 3) Kepala Dinas Pekerjaan Umum dan Penataan Ruang, Kota Surakarta \\ Jl. Ir. Sutami 36A, Surakarta 57126; Telp. 0271-634524. \\ Email: edosuryo017@gmail.com
}

\begin{abstract}
Laweyan village is one of the most village in Surakarta which must often get flooded. It is flown through by Premulung river and there is the confluence between Premulung river and Brojo river. The mapping flood impact area is one solution to solve the flood issue. The flood impact area analysis is measured based on rainfall data, river data and contour map of Laweyan village. Flood analysis and mapping ware done with HEC-RAS software. They are unsteady flow simulation, with flow return period of 5 years, 10 years, 25 years, 50 years and maximum two daysrainfall.

The results of this study indicate that flood analysis with a return period of 5 and 10 years does not cause flood phenomenon. The flood impact area with flow return period of 25 years is 14,081.59 $\mathrm{m}^{2}$ with flood duration 30 minute and impact area is 6.08\%. The flood impact area with flow return period of 50 years is $37.518,82 \mathrm{~m}^{2}$ with flood duration 1.5 hours and impact area is $16.20 \%$. The flood impact area with maximum two-days flow is $79.824,68 \mathrm{~m}^{2}$ with flood duration 2 hours and impact area is $34.46 \%$.
\end{abstract}

Key words: flood analysis, flood mapping, HEC-RAS, Soil Conservation Service.

\begin{abstract}
Abstrak
Kelurahan Laweyan merupakan salah satu kelurahan di Kota Surakarta yang sering tergenang banjir. Kelurahan Laweyan dilewati oleh Sungai Premulung dan terdapat pertemuan Sungai Premulung dan Sungai Brojo. Salah satu bentuk dari penanganan banjir yaitu dengan memetakan kawasan terdampak banjir. Analisis kawasan terdampak banjir dilakukan berdasarkan data hujan yang terjadi, data sungai dan peta kontur Kelurahan Laweyan. Debit rencana dihitung dengan metode Hidrograf Satuan Sintetis Soil Conservation Service. Analisis banjir dan pemetaan dilakukan dengan bantuan software HEC-RAS. Dengan simulasi aliran unsteady flow, dengan debit periode ulang 5 tahun, 10 tahun, 25 tahun, 50 tahun, dan hujan dua harian maksimum.

Hasil penelitian ini menunjukkan bahwa analisis banjir dengan debit periode ulang 5 dan 10 tahun tidak terjadi banjir. Luasan wilayah tergenang banjir dengan debit periode ulang 25 tahun seluas $14.081,59 \mathrm{~m}^{2}$ dengan durasi genangan 30 menit dan persentase wilayah tergenang sebesar $6,08 \%$. Luasan wilayah terganang banjir dengan debit periode ulang 50 tahun seluas $37.518,82 \mathrm{~m}^{2}$ dengan durasi genangan 1,5 jam dan persentase wilayah tergenang sebesar 16,20\%. Luasan wilayah terganang banjir dengan debit dua harian maksimum seluas 79.824,68 $\mathrm{m}^{2}$ dengan durasi genangan 2 jam dan persentase wilayah tergenang sebesar $34,46 \%$.
\end{abstract}

Kata kunci: analisis banjir, pemetaan banjir, HEC-RAS, HSS Soil Conservation Service. 


\section{PENDAHULUAN}

Dengan adanya pembangunan infrastruktur yang sedang berkembang pesat maka diperlukan adanya upaya untuk Banjir merupakan salah satu permasalahan yang banyak terjadi pada kota-kota di Indonesia, utamanya pada musim hujan. Banjir tergolong bencana alam yang menjadi permasalahan tahunan dan menimbulkan kerugian yang besar. Karena banjir biasanya terjadi pada daerah dengan cakupan yang luas, sehingga menimbulkan banyak korban.

Banjir termasuk peristiwa alam yang terjadi karena kapasitas tampungan saluran atau sungai tidak mampu menampung volume air yang melebihi kapasitas tampungan, sehingga terjadi luapan air di wilayah sekitar sungai. Banjir biasanya dapat terjadi karena curah hujan yang tinggi, penyempitan saluran, penggunaan tata guna lahan yang salah, sedimentasi yang tinggi, atau arus balik (Rintis, 2014).

Kota Surakarta merupakan salah satu Kota di Jawa Tengah, yang sering mengalami bencana banjir. Kota Surakarta berada pada daerah dataran rendah yang berada diantara Gunung Merbabu dan Gunung Lawu. Kota Surakarta juga dibatasi oleh sungai besar, yaitu sungai Bengawan Solo pada sisi selatan Kota Surakarta. Dari Sungai Bengawan Solo dan anak Sungai Bengawan Solo Kota Surakarta sering mengalami banjir.

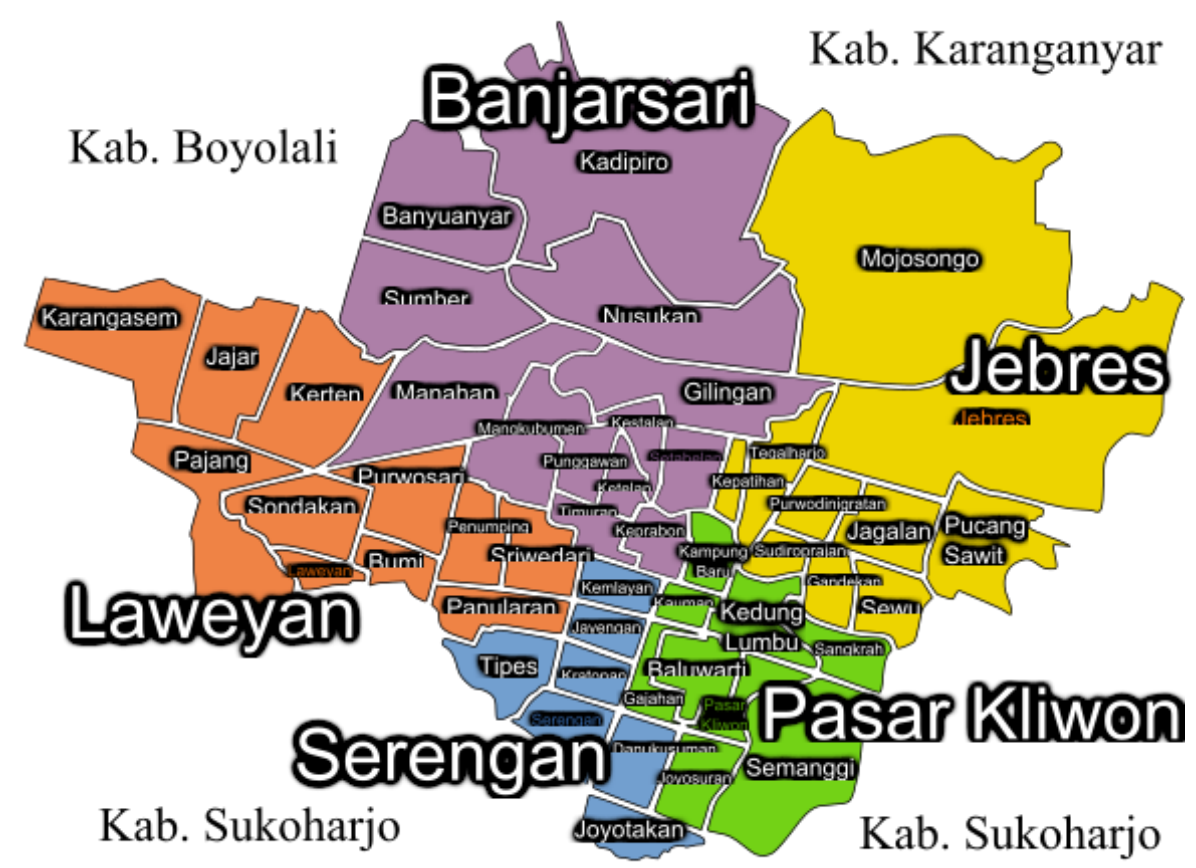

Gambar 1. Peta Kota Surakarta

Kelurahan Laweyan berada pada administrasi Kecamatan Laweyan, Surakarta. Kelurahan Laweyan merupakan kelurahan yang berada diantara Sungai Premulung dan jalan Dr. Radjiman. Pada Kelurahan Laweyan juga terdapat pertemuan Sungai Premulung dan Sungai Brojo, sehingga pada penelitian ini menggunakan dua Daerah Aliran Sungai (DAS) Premulung dan Brojo. Kelurahan Laweyan termasuk kelurahan yang sering mengalami banjir. Banjir pada Kelurahan Laweyan sering terjadi pada daerah pinggir sungai, karena sungai pada Kelurahan Laweyan masih merupakan sungai alami. Sehingga perlu diadakan analisis banjir dan pemetaan banjir pada Kelurahan Laweyan.

Penelitian ini dilakukan untuk memperhitungkan luasan dan elevasi banjir pada Kelurahan Laweyan melalui analisis banjir. Analisis banjir merupakan cara memprediksi kemungkinan terjadinya banjir, berdasarkan data historis curah hujan yang telah ada dari tahun-tahun sebelumnya dan data geometri dari sungai yang berkaitan. Sehingga ketika terjadi hujan dengan kala ulang tertentu dapat diprediksi besaran volume debit aliran yang akan melalui saluran Sungai Premulung dan Brojo, Laweyan. Dengan menggunakan debit banjir periode ulang yang lazim digunakan pada analisis sungai yaitu kala ulang $\mathrm{Q}_{5}, \mathrm{Q}_{10}, \mathrm{Q}_{25}$ dan $\mathrm{Q}_{50}$ tahun.

Analisis banjir dilakukan secara Unsteady flow karena titik analisis terjadi pada tempuran sungai. Untuk menganalisis secara unsteady flow, perlu menggunakan debit aliran jam-jaman. Untuk menghitung distribusi hujan jam-jaman, digunakan metode Alternating Block Method (ABM). Selanjutnya debit aliran sungai diperoleh dengan menggunakan Hidrograf Satuan Sintetis (HSS) Soil Conservation Service(SCS). 
Untuk melakukan analisis pada analisis dan pemetaan banjir Kelurahan Laweyan dilakukan dengan menggunakan software HEC-RAS. HEC-RAS merupakan salah satu software yang diperuntukkan untuk analisis pada bidang hidrolika. Software ini juga mampu melakukan analisis flood routing berdasarkan dimensi dari saluran sungai dan debit banjir. Pada pembuatan peta genangan banjir dilakukan dengan software ArcGIS untuk setiap periode ulang.

\section{LANDASAN TEORI \\ Dasar Teori}

Banjir merupakan bencana musiman yang sering terjadi pada kota-kota besar di Indonesia. Analisis dan solusi permasalahan banjir merupakan suatu permasalahan yang kompleks. Solusi permasalahan banjir melibatkan banyak disiplin bidang keilmuan, baik dari ekonomi, lingkungan, sosial, institusi dan teknik. Dalam bidang teknik analisis banjir meliputi analisis penyebab banjir, hidrologi, dan hidrolika.

Penyebab banjir utamanya disebabkan oleh kapasitas tampungan sungai yang tidak mampu menampung air yang mengalir melalui sungai. Sehingga air pada sungai meluap ke daerah sekitar sungai, yang menyebabkan banjir. Ketidak mampuan sungai dalam menampung air yang mengalir, dapat disebabkan oleh beberapa hal, baik karena kapasitas awal sungai yang kecil, aliran air yang terlalu besar karena hujan deras, penyempitan badan sungai, sedimen, ataupun permasalahan lain.

Hujan merupakan komponen masukan yang paling penting dalam proses analisis hidrologi, karena kedalaman curah hujan (rainfall depth) yang turun dalam satu DAS akan dialirkan menjadi aliran sungai, baik melalui limpasan permukaan (surface runoff), aliran antara (interflow, sub-surface runoff), maupun sebagai aliran air tanah (groundwater flow) (Sri Harto, 1993).

Hidrograf Satuan Sintetis merupakan hidrograf yang dibuat berdasarkan pada karakteristik fisik dari DAS, karena data hidrologi tidak tersedia untuk dilakukan perhitungan dengan hidrograf satuan biasa. Salah satu Hidrograf Satuan Sintetis yang biasa digunakan yaitu metode SCS (Soil Conservation Service).

HEC-RAS (River Analysis System) merupakan software untuk memodelkan aliran suatu sungai, dengan prinsip hidrolika yang di kembangkan oleh Hydrologic Engineering Center (HEC) yang merupakan satu devisi di dalam Institute for Water Resources (IWR), di bawah US Army Corps of Engineers (USACE). HEC-RAS mampu melakukan pemodelan satu dimensi aliran baik berupa aliran permanen (Steady flow) maupun aliran tidak permanen (Unsteady flow). HECRAS merupakan software yang mengintegrasikan fitur grafik, user interface, analisis hidraulik, manajemen dan penyimpanan data, grafik, serta hasil.

\section{METODE PENELITIAN}

Penelitian ini menggunakan data primer dan data sekunder. Data primer yang didapat berdasarkan survey cross section sungai Brojo. Data sekunder meliputi data hujan harian stasiun Hujan Nepen dan Pabelan, data situasi sungai Premulung, peta kontur Kota Surakarta dan peta DAS Premulung.

\section{HASIL DAN PEMBAHASAN}

\section{Daerah Aliran Sungai}

Daerah Aliran Sungai (DAS) merupakan daerah tangkapan air yang masuk kedalam sungai, DAS dibatasi oleh punggung-punggung bukit. Untuk analisis banjir pada Kelurahan Laweyan diperlukan dua wilayah DAS, yaitu DAS Premulung dan Brojo, karena pertemuan kedua sungai terletak pada Kelurahan Laweyan. DAS Premulung dan Brojo disajikan dalam Gambar 2.

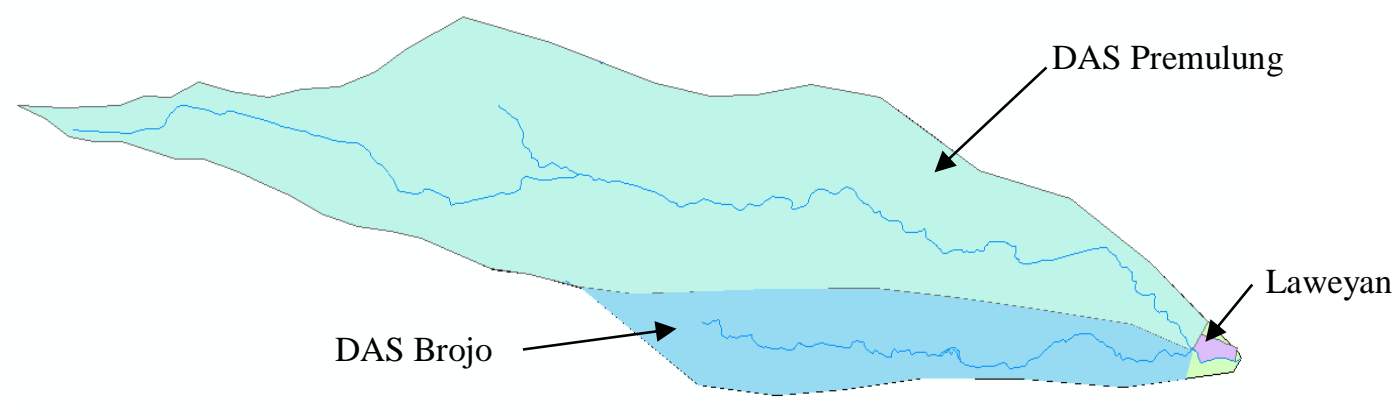

Gambar 2 Daerah Aliran Sungai Premulung dan Brojo 


\section{Uji Kepanggahan}

Uji kepanggahan dilakukan dengan metode kurva massa ganda (double mass curve). Uji kepanggahan dilakukan dengan cara merekap data hujan tahunan selama 20 tahun terakhir, dari mulai tahun 1998 sampai dengan tahun 2017. Grafik kurva massa ganda merupakan hasil dari perbandingan komulatif hujan tahunan masing-masing stasiun hujan. Dengan stasiun hujan Pabelan sebagai sumbu X dan stasiun hujan Nepen sebagai sumbu Y. Data hujan dapat dikatakan panggah apabila memiliki nilai determinastik $\left(\mathrm{R}^{2}\right)$ yang mendekati 1 atau mendekati linier. Dari analisis dengan Ms. Excel di dapat Gambar 3.

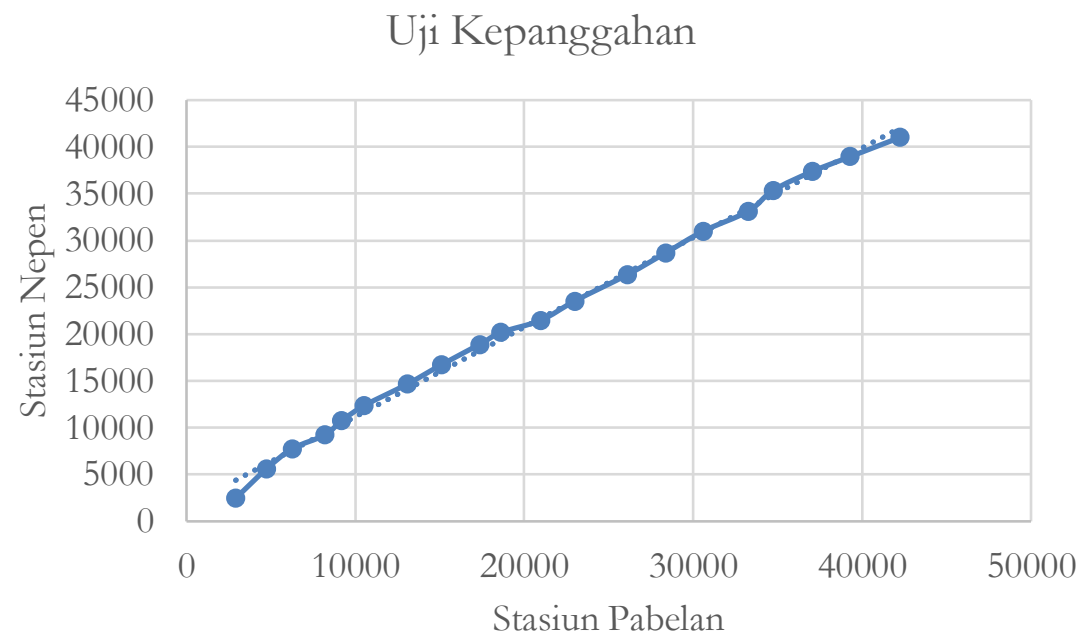

Gambar 3 Grafik Kurva Massa Ganda

\section{Hujan Kawasan}

Hujan kawasan dianalisis menggunakan metode rata-rata aljabar dengan data hujan maksimum harian pada stasiun hujan Nepen dan Pabelan. Metode rata-rata aljabar merupakan metode yang paling sederhana, yaitu dengan cara menjumlahkan besarnya hujan dibagi dengan jumlah stasiun hujan, yang kemudian dipilih nilai yang terbesar dari hujan harian maksimum tiap stasiun untuk menjadi hujan maksimum kawasan. Hujan dua harian maksimum merupakan hujan yang di asumsikan terjadi selama dua hari secara berturut-turut. Yang kemudian dari nilai hujan dua hari tersebut di jumlahkan menjadi hujan dua harian maksimum. Untuk hujan kawasan dua harian di analisis dengan metode rata-rata aljabar seperti pada hujan kawasan harian maksimum.

\section{Distribusi Hujan}

Dari analisis distribusi hujan dengan menggunakan metode Log Person III yang didasarkan pada SNI 2415-2016 tentang Tata Cara Perhitungan Debit Banjir Rencana. Analisis distribusi hujan Log Person III didapatkan hasil seperti dalam Tabel 1.

Tabel 1 Tabel Log Person III

Log Person III

\begin{tabular}{|c|c|c|c|c|c|c|}
\hline NO & TAHUN & $\mathbf{X}$ & $\log X$ & $\mathbf{X}-\mathbf{X}_{\mathrm{t}}$ & $\left(\mathrm{X}-\mathrm{X}_{\mathrm{t}}\right)^{2}$ & $\left(\mathrm{X}-\mathrm{X}_{\mathrm{t}}\right)^{3}$ \\
\hline 1 & 1998 & 57,50 & 1,7597 & $-0,0910$ & 0,0083 & $-0,0008$ \\
\hline 2 & 1999 & 72,60 & 1,8609 & 0,0102 & 0,0001 & 0,0000 \\
\hline 3 & 2000 & 58,50 & 1,7672 & $-0,0835$ & 0,0070 & $-0,0006$ \\
\hline 4 & 2001 & 46,50 & 1,6675 & $-0,1832$ & 0,0336 & $-0,0062$ \\
\hline 5 & 2002 & 47,50 & 1,6767 & $-0,1740$ & 0,0303 & $-0,0053$ \\
\hline 6 & 2003 & 50,50 & 1,7033 & $-0,1474$ & 0,0217 & $-0,0032$ \\
\hline 7 & 2004 & 61,50 & 1,7889 & $-0,0618$ & 0,0038 & $-0,0002$ \\
\hline 8 & 2005 & 81,00 & 1,9085 & 0,0578 & 0,0033 & 0,0002 \\
\hline 9 & 2006 & 71,00 & 1,8513 & 0,0006 & 0,0000 & 0,0000 \\
\hline
\end{tabular}




\begin{tabular}{ccccccc}
10 & 2007 & 91,50 & 1,9614 & 0,1107 & 0,0123 & 0,0014 \\
\hline 11 & 2008 & 75,50 & 1,8779 & 0,0273 & 0,0007 & 0,0000 \\
\hline 12 & 2009 & 133,50 & 2,1255 & 0,2748 & 0,0755 & 0,0208 \\
\hline
\end{tabular}

Tabel 1 Lanjutan

\begin{tabular}{|c|c|c|c|c|c|c|}
\hline 13 & 2010 & 81,50 & 1,9112 & 0,0605 & 0,0037 & 0,0002 \\
\hline 14 & 2011 & 81,50 & 1,9112 & 0,0605 & 0,0037 & 0,0002 \\
\hline 15 & 2012 & 79,50 & 1,9004 & 0,0497 & 0,0025 & 0,0001 \\
\hline 16 & 2013 & 50,50 & 1,7033 & $-0,1474$ & 0,0217 & $-0,0032$ \\
\hline 17 & 2014 & 86,50 & 1,9370 & 0,0863 & 0,0075 & 0,0006 \\
\hline 18 & 2015 & 86,50 & 1,9370 & 0,0863 & 0,0075 & 0,0006 \\
\hline 19 & 2016 & 82,00 & 1,9138 & 0,0631 & 0,0040 & 0,0003 \\
\hline \multirow[t]{6}{*}{20} & 2017 & 71,00 & 1,8513 & 0,0006 & 0,0000 & 0,0000 \\
\hline & Jumlah & & 37,0137 & & 0,2470 & \\
\hline & Rerata & & 1,8507 & & & \\
\hline & S.dev & & 0,1140 & & & \\
\hline & Kemenc & & 0,0003 & & & \\
\hline & $\mathrm{CS}$ & & 0,1984 & & & \\
\hline
\end{tabular}

\section{Uji Kecocokan Distribusi Hujan}

Uji kecocokan distribusi dilakukan untuk mengetahui apakah metode distribusi hujan cocok atau tidak dengan data hujan yang ada. Pada uji Smirnov-Kolmogorov untuk distribusi hujan Log Person III dengan tingkat ketelitian 5\%. Berdasarkan hasil uji Sminov-Kologorov pada Tabel 4.6 diperoleh $\Delta$ maksimum $=0,07$, dan dibandingkan dengan Tabel 3.2 untuk jumlah data hujan (n) sebanyak 20 tahun maka akan didapatkan $\Delta$ kritis $=0,29$. Dengan syarat $\Delta$ maksimum $<\Delta$ kritis, maka distribusi hujan dapat diterima berdasarkan uji Smirnov-Kolmogorv.

\section{Hujan Periode Ulang}

Perhitungan hujan periode ulang ya itu dengan cara mengembalikan nilai logaritma dari distribusi hujan tersebut. Hasil perhitungan hujan periode ulang disajikan dalam Tabel 2.

Tabel 2 Hujan Periode Ulang

\begin{tabular}{ccccc} 
KALA ULANG & $\mathrm{K}$ & K.S.SEv & $\mathrm{X}_{\mathrm{t}}+\mathrm{K} . \mathrm{sd}$ & $\mathrm{Q}_{\mathrm{t}}(\mathrm{mm} / \mathrm{jam})$ \\
\hline 5 & 0,8301 & 0,0946 & 1,9453 & 88,1731 \\
\hline 10 & 1,3009 & 0,1483 & 1,9990 & 99,7729 \\
\hline 25 & 1,8175 & 0,2072 & 2,0579 & 114,2660 \\
\hline 50 & 2,1582 & 0,2461 & 2,0968 & 124,9578
\end{tabular}

\section{Hidrograf Satuan Sintetis}

Dari hasil debit jam-jaman SCS periode ulang 5, 10, 25 dan 50 tahun maka dapat dibuat grafik hidrograf SCS. Grafik hidrograf untuk periode ulang di tampilkan dalam Gambar 4. 
HSS SCS Premulung

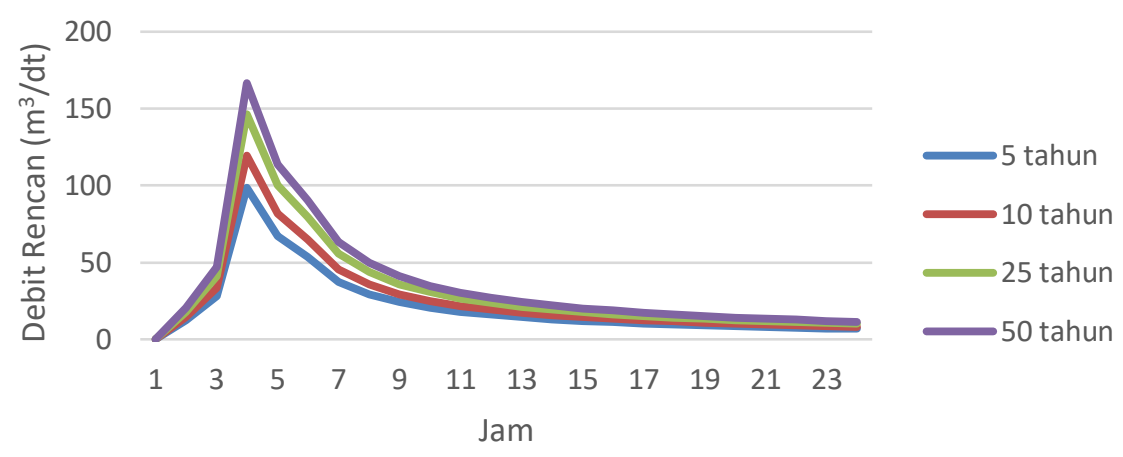

Gambar 4 Grafik HSS SCS Premulung

Dari hasil debit jam-jaman SCS periode ulang 5, 10, 25 dan 50 tahun maka dapat dibuat grafik hidrograf SCS. Grafik hidrograf untuk periode ulang Sungai Brojo di tampilkan dalam Gambar 5.

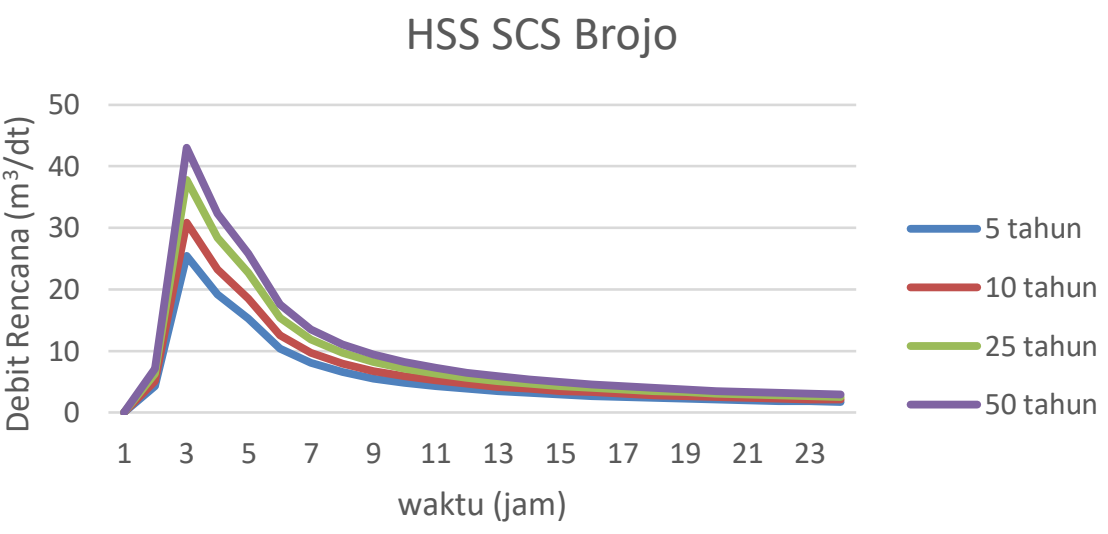

Gambar 5 Grafik HSS SCS Brojo

\section{Analisis Banjir}

Analisis banjir pada Kelurahan Laweyan dilakukan dengan HEC-RAS. HEC-RAS mengelola data geometry dan debit aliran sungai menjadi ketinggian, durasi dan pemetaan banjir. HEC-RAS menganalisis secara Hidrolika, dengan simulasi aliran unsteady flow.

\section{Pemetaan Banjir}

Berdasarkan hasil running HEC-RAS didapatkan ketinggian muka air banjir dan pemetaan luasan genangan banjir dalam bentuk RAS Mapper. Pemetaan banjir berdasarkan hasil HEC-RAS pada RAS Mapper disajikan dalam Gambar 6. 


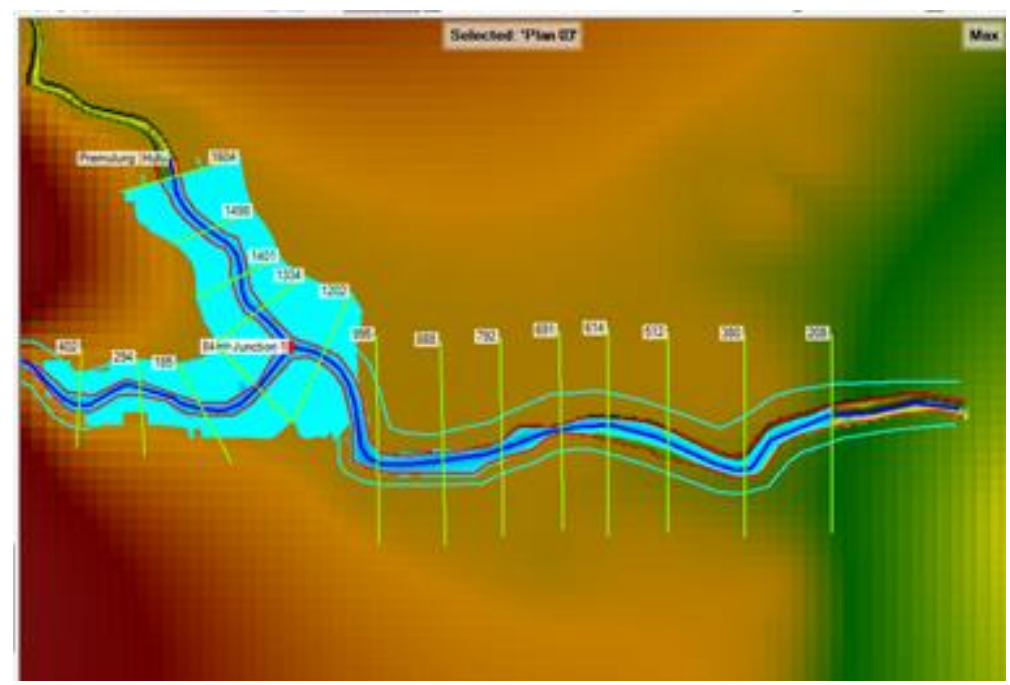

Gambar 6 Banjir RAS Mapper

Hasil Ras Mapper selanjutnya di export diproses kedalam format ArcGIS sehingga dapat dilakukan penggambaran peta. Dalam software ArcGIS dibuat layout, kelengkapan dan skala peta.

\section{KESIMPULAN}

Berdasarkan pada analisis dan pembahasan dapat di ambil kesimpulan sebagai berikut:

1. Debit banjir maksimum untuk setiap periode ulang pada Sungai Premulung dan Sungai Brojo disajikan dalam Tabel 3.

Tabe1 3 Debit Maksimum Setiap Periode Ulang

\begin{tabular}{ccc}
\multirow{2}{*}{$\begin{array}{c}\text { Periode Ulang } \\
\text { (tahun) }\end{array}$} & \multicolumn{2}{c}{ Sungai } \\
\cline { 2 - 3 } & Premulung $\left(\mathrm{m}^{3} / \mathrm{dt}\right)$ & Brojo $\left(\mathrm{m}^{3} / \mathrm{dt}\right)$ \\
\hline 5 & 98,5435 & 25,4588 \\
\hline 10 & 119,4518 & 30,8604 \\
\hline 25 & 146,3309 & 37,8046 \\
\hline 50 & 166,5792 & 43,0358
\end{tabular}

Untuk debit banjir maksimum dua harian untuk Sungai Premulung sebesar 178,78 $\mathrm{m}^{3} / \mathrm{dt}$ dan Sungai Brojo sebesar $49,087 \mathrm{~m}^{3} / \mathrm{dt}$.

2. Elevasi muka air banjir dari analisis Unsteady flow menggunakan HEC-RAS dengan debit periode ulang 5, 10, 25 dan 50 tahun serta dua harian didapatkan elevasi banjir seperti dalam Tabel 4.

Tabel 4 Elevasi dan Ketinggian Muka Air Banjir

\begin{tabular}{llllll}
\multirow{2}{*}{ STA } & \multicolumn{5}{c}{ Ketinggian muka air banjir $(\mathrm{cm})$} \\
\cline { 2 - 6 } & 5 th & 10 th & 25 th & 50 th & 2 hari \\
\hline Sungai Premulung & & & \\
\hline 208 & - & - & - & - & - \\
\hline 280 & - & - & - & - & - \\
\hline 512 & - & - & - & - & - \\
\hline 614 & - & - & - & - & - \\
\hline 691 & - & - & - & - & - \\
\hline 792 & - & - & - & - & 13 \\
\hline 888 & - & - & - & - & 19
\end{tabular}




\begin{tabular}{cccccc}
995 & - & - & - & - & 20 \\
\hline 1202 & - & - & - & 5 & 37 \\
\hline 1334 & - & - & - & 20 & 53 \\
\hline $1401-$ & - & - & 17 & 40 \\
\hline 1498 & - & - & 1 & 30 & 57 \\
\hline 1604 & - & - & 10 & 40 & 62 \\
\hline
\end{tabular}

Sungai Bojo

\begin{tabular}{cccccc}
\hline 84 & - & - & - & 5,00 & 30 \\
\hline 185 & - & - & - & 7,00 & 30 \\
\hline 294 & - & - & - & 7,00 & 30 \\
\hline 402 & - & - & - & 8,00 & 30 \\
\hline 529 & - & - & - & - & -
\end{tabular}

3. Berdasarkan hasil analisis HEC-RAS dan pemetaan dari Arc-GIS, maka akan didapatkan luasan dan persentase luasan tergenang banjir Kelurahan Laweyan. Luasan dan persentase daerah tergenang disajikan dalam tabel 5.

Tabel 5 Luasan, durasi dan Persentase Banjir

\begin{tabular}{cccc}
$\begin{array}{c}\text { Periode } \\
\text { Ulang }\end{array}$ & $\begin{array}{c}\text { Luasan } \\
\left(\mathrm{m}^{2}\right)\end{array}$ & $\begin{array}{c}\text { Durasi } \\
(\mathrm{jam})\end{array}$ & $\begin{array}{c}\text { Prosentase Luasan } \\
\text { Tergenang }(\%)\end{array}$ \\
\hline 5 & - & 0 & 0,00 \\
\hline 10 & - & 0 & 0,00 \\
\hline 25 & $14.081,59$ & 0,5 & 6,08 \\
\hline 50 & $37.518,82$ & 1,5 & 16,20
\end{tabular}

4. Berdasarkan hasil analisis dari HEC-RAS dan pemetaan dari Arc-GIS, didapatkan peta pemetaan banjir untuk periode ulang 5,10,25, dan 50 tahun serta banjir dua harian maksimum yang terjadi pada tanggal 31 Desember 2008, dan 1 Januari 2009. Peta pemetaan banjir disajikan dalam Gambar 4-8.

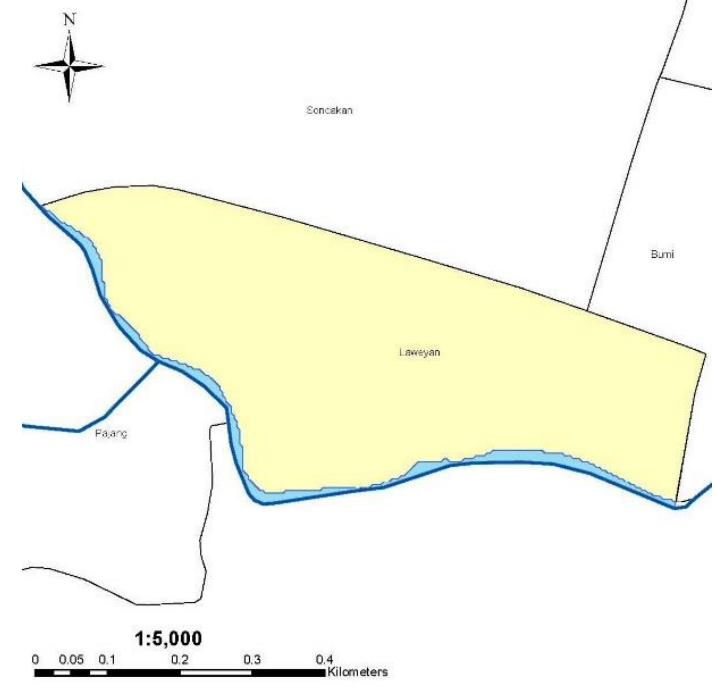

Gambar 7 Pemetaan Banjir Dengan Debit Periode Ulang 5 Tahun

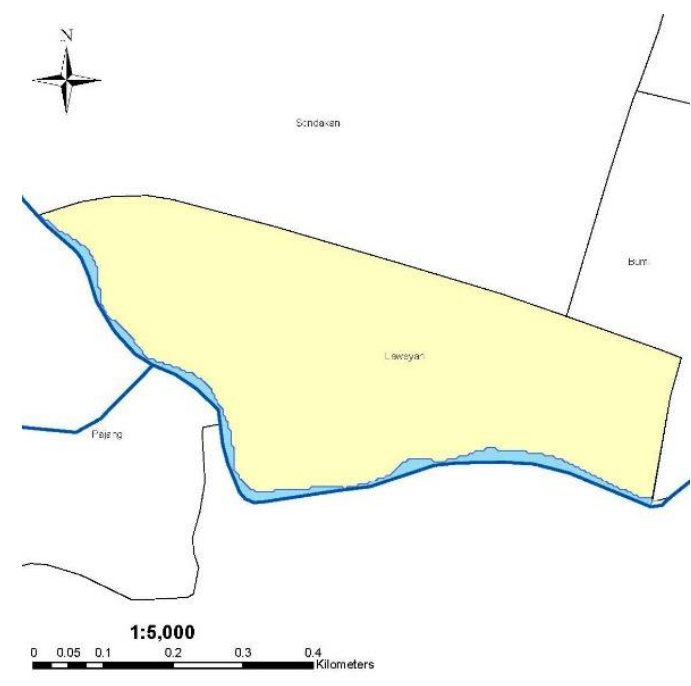

Gambar 8 Pemetaan Banjir Dengan Debit Periode Ulang 10 Tahun 


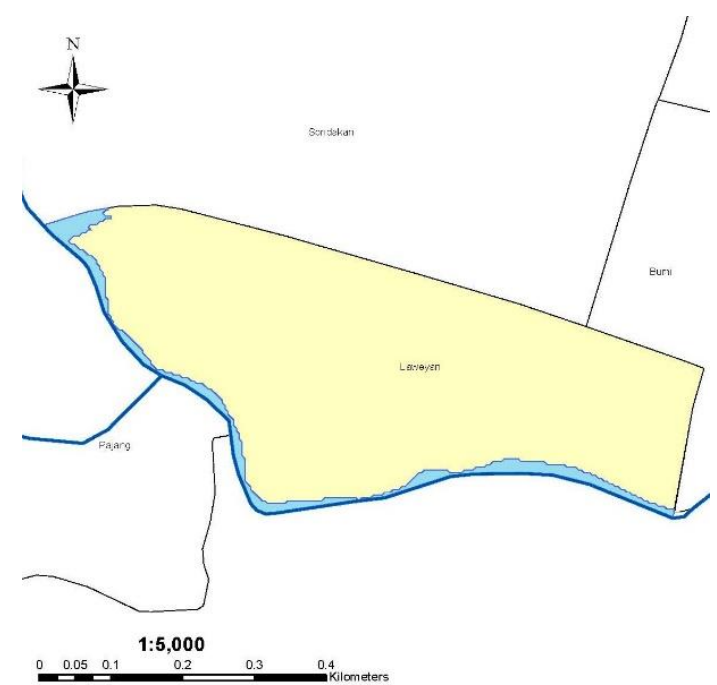

Gambar 9 Pemetaan Banjir Dengan Debit Periode Ulang 25 Tahun

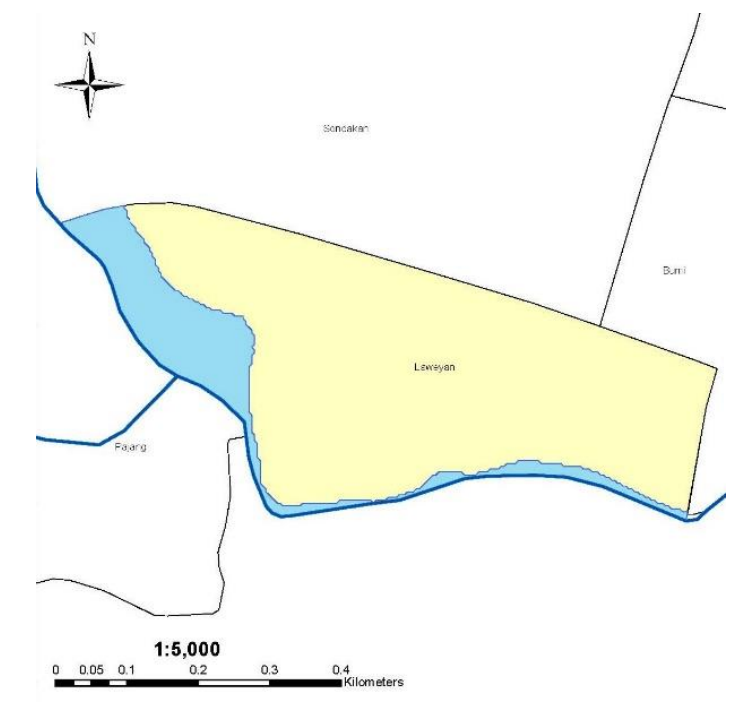

Gambar 10 Pemetaan Banjir Dengan Debit Periode Ulang 50 Tahun

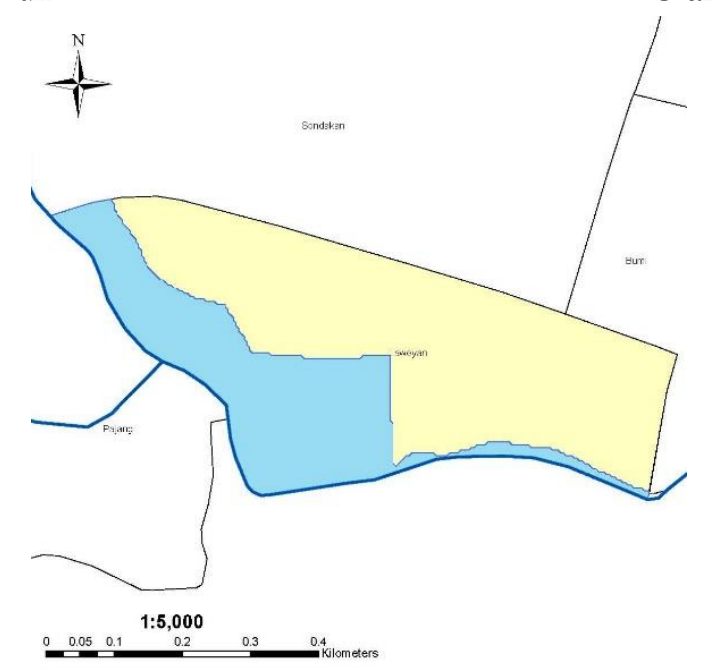

Gambar 11 Pemetaan Banjir Dengan Debit Dua Harian Maksimum

\section{REKOMENDASI}

1. Tersedianya data peta digital yang lebih detail,

2. Tersedia peta kontur yang lebih rapat,

3. Memperhitungkan saluran drainase yang ada,

4. Memperhitungkan aliran yang masuk,

5. Mempertimbangkan adanya bangunan di sekitar sungai, agar dapat membuat peta genangan yang lebih akurat dan estimasi kerusakan bangunan.

\section{REFERENSI}

Rintis Hadiani, 2014, Penelusuran Banjir di DAS Temon Dengan Metode Muskingum-Cunge Menggunakan Hidrocad, Skripsi, Jurusan Teknik Sipil, Universitas Sebelas Maret, Surakarta.

Sri Harto, 1985, Pengkajian Sifat Dasar Hidrograf-Satuan Sungai-sungai di pulau Jawa Untuk Perkiraan Banjir, Desertasi, Universitas Gajab Mada, Yogyakarta. 